\title{
The Berlin Affective Word List Reloaded (BAWL-R)
}

\author{
MeLisSa L.-H. Võ \\ Ludwig-Maximilians-Universität München, Munich, Germany \\ and Edinburgh University, Edinburgh, Scotland \\ AND \\ Markus Conrad, Lars Kuchinke, Karolina Urton, \\ Markus J. Hofmann, AND ARTHUR M. JaCobS \\ Freie Universität Berlin, Berlin, Germany
}

\begin{abstract}
The study presented here provides researchers with a revised list of affective German words, the Berlin Affective Word List Reloaded (BAWL-R). This work is an extension of the previously published BAWL (Võ, Jacobs, \& Conrad, 2006), which has enabled researchers to investigate affective word processing with highly controlled stimulus material. The lack of arousal ratings, however, necessitated a revised version of the BAWL. We therefore present the BAWL-R, which is the first list that not only contains a large set of psycholinguistic indexes known to influence word processing, but also features ratings regarding emotional arousal, in addition to emotional valence and imageability. The BAWL-R is intended to help researchers create stimulus material for a wide range of experiments dealing with the affective processing of German verbal material.
\end{abstract}

Imagine yourself winning the lottery jackpot. Then picture yourself lying on a pristine beach listening to the waves rolling in. You probably have positive emotions in both situations but feel different levels of emotional arousal. The same holds true for negative emotions-for example, being afraid of taking a test, as compared with feeling down on a rainy day. A framework that classifies such different affective experiences characterizes emotions along at least two orthogonal dimensions: valence, ranging from pleasant to unpleasant, and arousal, ranging from calm to excited (e.g., Bradley \& Lang, 1999; Lang, Greenwald, Bradley, \& Hamm, 1993; Russel, 1980).

In a previous study, we provided a database with emotional valence and imageability ratings for more than 2,200 German words, forming the Berlin Affective Word List (BAWL; Võ, Jacobs, \& Conrad, 2006). This has subsequently allowed researchers, particularly those conducting experiments in German, to control their experimental material not only with regard to valence and imageability ratings, but also according to variables known to systematically influence word processing - that is, word frequency, number of letters, number of syllables, and number and frequency of orthographic neighbors, as well as number and frequency of higher frequency orthographic neighbors (e.g., Kuchinke et al., 2006; Võ et al., 2008). Although the BAWL remains one of the few German word databases that provide emotional valence and imageability ratings (see also Hager \& Hasselhorn, 1994), in addition to a great number of psycholinguistic indexes, the need for additional information regarding the arousal dimension has led us to conduct a follow-up project. Thus, the study reported here was designed to update the previous version of the BAWL with ratings on arousal, while additionally extending the corpus by more than 700 words. Before we describe the BAWL-Reloaded (BAWL-R) in further detail, we will briefly review some work on the effects of arousal on cognitive processing, in order to highlight the need for control of the arousal dimension when affective processing is investigated.

In a majority of studies, the effects of affective content on memory processes have been investigated by comparing neutral events with events both negative and arousing, showing memory enhancement for such affective stimuli (for a review, see McGaugh, 2003). However, this had left unanswered the question of the relative contributions of both affective dimensions. As a result, effects of arousal on recognition memory have been reported regardless of the underlying emotional valence (e.g., Anderson, Wais, \& Gabrieli, 2006; Cahill \& MacGaugh, 1998; for reviews, see Hamann, 2001; McGaugh, 2006; Phelps, 2006). Emotional arousal can influence memory via factors that act during memory encoding (attention and elaboration), as well as factors that modulate memory consolidation enhancing explicit memory for both pleasant and unpleasant emotional events. It could be shown, for example, that emotional arousal increases the amount of attention di- 
rected to affective stimuli (e.g., Anderson, 2005; Bradley, 1994; Keil \& Ihssen, 2004). Further support for differential effects of either emotional valence or arousal stems from the finding that different brain regions are activated during affective processing depending on the relative position of the event within the valence-arousal space (e.g., Anderson et al., 2003; Dolcos, LaBar, \& Cabeza, 2004; Kensinger, 2004; Phelps \& Anderson, 1997). Anderson et al. (2003), for example, independently manipulated valence and arousal dimensions. They provided evidence that amygdala activation was related to arousal irrespective of valence, whereas activity in the orbitofrontal cortex mirrored valence regardless of arousal. Across studies, the amygdala has been consistently implicated as playing a key role in the processing of highly arousing events, suggesting that the amygdala is not simply a fear and reward system, but is instead sensitive to arousal-related properties of valenced stimuli in general (see Olsson \& Ochsner, 2008).

Most of the studies on affective processing have used pictorial stimulus materials. However, due to the high degree of experimental control, an increasing number of studies have started to use word-based stimulus materials for studying the influence of affective content on memory processes (e.g., Danion, Kauffmann-Muller, Grangé, Zimmermann, \& Greth, 1995; Kuchinke et al., 2006; Maratos, Allan, \& Rugg, 2000; Richardson, Strange, \& Dolan, 2004; Siegle, Ingram, \& Matt, 2002; Võ et al., 2008; Windmann \& Kutas, 2001). Although emotional arousal mediated by verbal stimuli seems to be less pronounced, as compared with highly arousing pictorial stimulus materials (Phelps, LaBar, $\&$ Spencer, 1997), there is evidence for effects of emotional arousal in word processing as well (e.g., Hofmann, Kuchinke, Tamm, Võ, \& Jacobs, 2009; Kissler, Assadollahi, \& Herbert, 2006; Kissler, Herbert, Peyk, \& Junghöfer, 2007; Scott, O'Donnel, Leuthold, \& Sereno, 2009; Thomas $\&$ LaBar, 2005). Scott and colleagues found early interactions between word frequency and emotion in event-related brain potentials (ERPs), using a lexical decision task. However, since highly arousing negative and positive words were contrasted with neutral, low-arousing words, the relative contributions of arousal and valence could not be fully ascertained. Hofmann and colleagues, on the other hand, explicitly manipulated both arousal and valence of words in an ERP study showing differential impact of arousal on lexical decision for positive and negative words. For positive words, shorter reaction times were observed regardless of the arousal level. In contrast, differences in the arousal level of negative words modulated behavioral responses: Whereas highly arousing negative words led to shorter reaction times, longer reaction times were observed when the arousal level of negative words was controlled such that low-arousing negative words did not differ from neutral words regarding their rated arousal level.

In order to investigate such nuances of affective processing, reliable stimulus databases are needed that allow for the control of a great number of subjective and objective variables. There have been a number of word databases providing information on variables such as imageability, concreteness, or word associations (e.g., Altarriba, Bauer, \& Benvenuto, 1999; Bird, Franklin, \& Howard, 2001; Bonin et al., 2003; Chiarello, Shears, \& Lund, 1999; Cortese \& Fugett, 2004; Ferrand, 2001; Hager \& Hasselhorn, 1994; New, Pallier, Brysbaert, \& Ferrand, 2004; Paivio, Yuille, \& Madigan, 1968; Ziegler, Stone, \& Jacobs, 1997). However, there are still only a few word databases that contain ratings on emotional valence (e.g., Siegle, 1994) and arousal (e.g., Bradley \& Lang, 1999; Redondo, Fraga, Padrón, \& Comesaña, 2007). The BAWL-R is the first database of German affective words that contains not only subjective ratings, such as valence, arousal, and imageability, but also a large set of psycholinguistic factors known to influence word perception (see Graf, Nagler, \& Jacobs, 2005).

\section{METHOD}

\section{Participants}

A total of 200 psychology students (165 female; mean age $=$ 27.14 years, $S D=9.11$ ) at the Freie Universität Berlin and the Katholische-Universität Eichstätt-Ingolstadt contributed to the final data set. The ratings of the words were obtained throughout the years 2007-2008.

\section{Materials and Procedure}

The BAWL-R is a list of over 2,900 German words taken from the CELEX database (Baayen, Piepenbrock, \& van Rijn, 1993) and based on the BAWL (Võ et al., 2006), which represents negative, neutral, and positive affective valences. For the 700 new words of the BAWL-R, all three ratings regarding valence, arousal, and imageability were collected; the remainder of the corpus was updated with arousal ratings. As in the previous version of the BAWL, emotional valence was rated on a 7-point scale ranging from -3 (very negative) through 0 (neutral) to +3 (very positive). Again, the 7-point imageability scale ranged from 1 (low imageability) to 7 (high imageability). Extending the previous version of the BAWL, arousal was rated on a 5-point scale ranging from 1 (low arousal) to 5 (high arousal), using the Self-Assessment Manikin (SAM; Lang, 1980). We decided to use SAMs for depicting increasing levels of arousal, since the German word for arousal ("Erregung") implies sexual connotations, which we circumvented by showing SAMs. However, we used the arousal SAMs as a 5-point scale instead of a 9-point scale. In a pilot arousal-rating study that included a 9-point scale with the possibility of marking points between the five depictions of the SAMs, participants did not make use of such fine-graded ratings. Therefore, we need to point out that a rating of 5 for arousal in the BAWL-R reflects the highest possible arousal rating for a word, whereas a rating of 5 in most other studies using SAMs depicts a word that is neither arousing nor calm.

Subsequently, mean ratings and standard deviations were calculated. The items were randomly presented in sets of 250-350 words to exclude the influence of primacy or recency effects on the participants' ratings. The complete BAWL-R can be obtained at www .fu-berlin.de/allgpsy/BAWL-R.

\section{Description of the Database}

As compared with the prior version of the BAWL, the BAWL$\mathrm{R}$ has a number of important additions. (1) The BAWL-R was extended with more than 700 additional words, amounting to a final list of almost 3,000 words, which will allow researchers to choose from an even broader range of affective words. (2) This also led to the inclusion of a third word class: In addition to 2,107 nouns and 504 verbs, the BAWL-R now includes 291 adjectives. (3) Another important word-processing variable - that is, type bigram frequency (taken from Hofmann, Stenneken, Conrad, \& Jacobs, 2007) — was added as the ninth psycholinguistic index contained in the BAWL-R. (4) We also added the variable accent to the database, which provides information on which syllable of a word is stressed during pronunciation. (5) Most important, the BAWL-R not only 
contains ratings on emotional valence and imageability, but also now lists ratings on emotional arousal.

The database is organized in columns as follows.

General:

WORD: The critical word in uppercase.

WORD_LOWERCASE: The critical word in lowercase.

WORD_ENGLISH: The English translation of the German word.

WORDCLASS: The class that the critical word is assigned to: nouns $(\mathrm{N})$, verbs $(\mathrm{V})$, and adjectives $(\mathrm{A})$.

Subjective Ratings:

VALENCE_MEAN: The mean valence ratings with negative values for negative valence, positive values for positive valence, and values around 0 for neutral valence.

VALENCE_SD: The standard deviation of valence ratings.

AROUSAL_MEAN: The mean arousal ratings, with 1 being lowarousing and 5 being high-arousing.

AROUSAL_SD: The standard deviation of arousal ratings.

IMAGEABILITY_MEAN: The mean imageability ratings, with 1 being hardly imageable and 7 very imageable.

IMAGEABILITY_SD: The standard deviation of imageability ratings.

Psycholinguistic Indexes:

LETTERS

SYLLABLES

PHONEMES

FREQUENCY (Ftot/1mil): This variable described the total frequency of appearance per million words.

NUMBER OF ORTHOGRAPHIC NEIGHBORS (N): Two words are considered orthographic neighbors when they share all the letters (in the same position) except one (Coltheart, Davelaar, Jonasson, \& Besner, 1977). This index counts the number of orthographic neighbors of the critical word.

FREQUENCY OF ORTHOGRAPHIC NEIGHBORS (FN): This index refers to the summed frequency of orthographic neighbors.

NUMBER OF HIGHER FREQUENCY ORTHOGRAPHIC NEIGHBORS (HFN): This variable lists the number of words that are higher frequency orthographic neighbors.

FREQUENCY OF HIGHER FREQUENCY ORTHOGRAPHIC NEIGHBORS (FHFN): This variable contains the summed frequency of words that are higher frequency orthographic neighbors.

BIGRAM FREQUENCY (BIGmean): This index provides information on the nonpositional mean token bigram frequency of the critical word - that is, the frequency of those words that contain the bigrams of the critical word regardless of their position within the word.
Table 1

Summary of Variables Included in the Berlin Affective Word List Reloaded With Means (Ms), Standard Deviations (SDs), and Range

\begin{tabular}{lrrr}
\hline \multicolumn{1}{c}{ Variable } & \multicolumn{1}{c}{$M$} & \multicolumn{1}{c}{$S D$} & \multicolumn{1}{c}{ Range } \\
\hline Valence & 0.06 & 1.25 & $-3.00-2.90$ \\
Arousal & 2.76 & 0.68 & $1.10-4.70$ \\
Imageability & 4.17 & 1.38 & $1.22-6.89$ \\
Letters & 6.43 & 1.52 & $2-10$ \\
Syllables & 2.16 & 0.67 & $1-6$ \\
Phonemes & 5.69 & 1.48 & $2-10$ \\
Frequency & 53.14 & 152.51 & $0-4,190$ \\
N & 1.61 & 2.31 & $0-18$ \\
FN & 254.79 & $2,735.93$ & $0-130,233$ \\
HFN & 0.57 & 1.19 & $0-11$ \\
FHFN & 216.76 & $2,262.67$ & $0-104,092$ \\
BIGmean & 229,580 & 155,674 & $8,024-839,507$ \\
Accent & 1.34 & 0.62 & $1-5$ \\
\hline
\end{tabular}

Note- $\mathrm{N}$, number of orthographic neighbors; FN, frequency of orthograophic neighbors; HFN, number of higher frequency orthographic neighbors; BIGmean, bigram frequency.

ACCENT: This variable indicates which syllable of the critical word is stressed when pronouncing the word. For example, when making cross-linguistic comparisons, this index will be of use.

Table 1 contains a summary of the statistics of the variables contained in the BAWL-R.

\section{RESULTS AND DISCUSSION}

Figure 1 depicts the quadratic function relating emotional arousal and emotional valence in the affective space.

The relation between emotional arousal and emotional valence can be described by the quadratic function $y=$ $0.15 x^{2}-0.25 x+2.53, R^{2}=.37$. The inverted U-shaped function is characterized by higher arousal values for emotionally valenced words. This boomerang-shaped distribution has also been reported by other studies for different languages, as well as for pictorial stimulus material (e.g., Bradley, Greenwald, Petry, \& Lang, 1992; Bradley \& Lang, 1999; Lang, Bradley, \& Cuth-

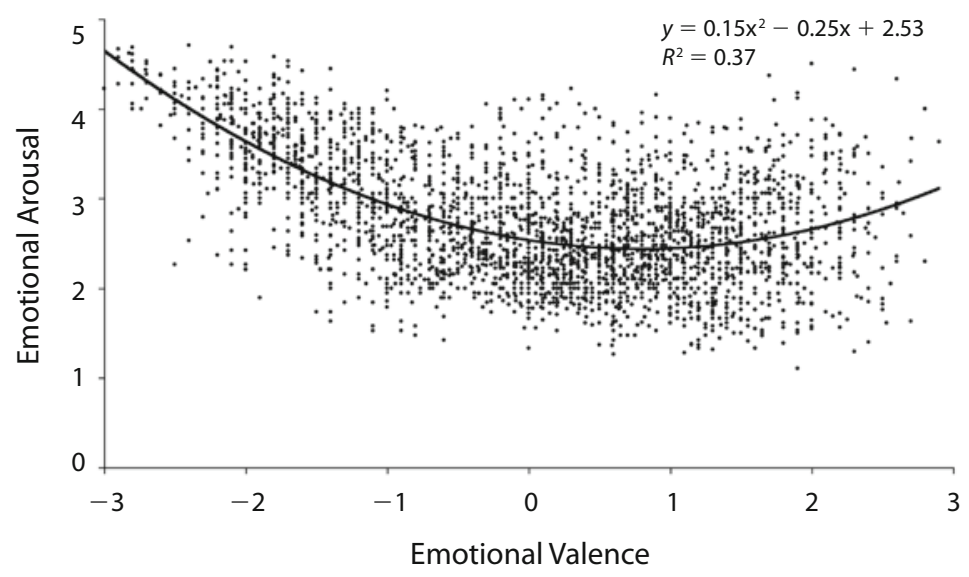

Figure 1. Distribution of mean values for all words of the Berlin Affective Word List Reloaded as a function of rated emotional valence and arousal. 
bert, 1998; Redondo et al., 2007). In addition, we found that the relationship between both dimensions in our sample is asymmetrical in that negative words tend to show higher arousal ratings than do positive words. This relationship seems to be constant across instruments that measure emotion from a bidimensional point of viewfor example, the English, as well as the Spanish, ANEW database (Bradley \& Lang, 1999; Redondo et al., 2007). Thus, it seems that an increasing degree of negative valence is accompanied by an increase in emotional arousal $\left(y=-0.64 x+2.35, R^{2}=.42\right)$, whereas this relation is weaker for positive valence $\left(y=0.12 x+2.38, R^{2}=\right.$ $.02)$. Weaker correlations between positive words and their rated arousal in our sample, as compared with other databases, are probably due to the fact that we have not included taboo words into BAWL-R. These are usually highly arousing, positively rated words, such as orgasm or sex (see Redondo et al., 2007).

As we have pointed out before, we used SAMs depicted on a 5-point rating scale to acquire arousal ratings for the BAWL-R. However, we need to make clear that this procedure is not based on Lang's (1980) theoretical and methodological approach to emotion, according to which both dimensions-emotional valence as well as emotional arousal - are bipolar. Although we agree that emotional valence is best represented by a bipolar dimension with a negative pole on the one side of the scale, a positive pole on the other, and neutral valences around the scale's center, we believe that emotional arousal can conceptually be better represented as a unipolar dimension with linearly increasing positive values of arousal ranging from low arousing (value of 1) to high arousing (value of 5). On the basis of this conceptualization, a 5-point scale allows detailed enough distinctions along the arousal dimension.

In sum, the present study was carried out within the framework of the dimensional perspective of emotion, which proposes the orthogonal dimensions of emotional valence and emotional arousal. Thus, in order to investigate affective word processing, both the valence and the arousal values of words have to be manipulated or controlled for. This necessitates a large word database, which provides ratings on both affective dimensions plus a range of information regarding psycholinguistic indexes known to influence word processing. The revised version of the BAWL, the BAWL-Reloaded, is the result of the growing demand for such a database. We hope that the BAWL-R will enable researchers to use highly controlled German verbal stimulus material for the study of emotion.

\section{AUTHOR NOTE}

This work was supported by the Deutsche Forschungsgemeinschaft (research unit "Conflicts as signals in cognitive systems," TP 3 Jacobs, JA 823/4-1; Research Grant JA 823/3-2) and the Cluster of Excellence "Languages of Emotion" to the Freie Universität Berlin. We thank Benny Briesemeister for calculating neighborhood and bigram frequency measures. Correspondence concerning this article should be addressed to M. L.-H. Võ, Visual Cognition Unit, Psychology Department, University of Edinburgh, 7 George Square, S32, Edinburgh EH8 9J2, Scotland (e-mail: melissa.vo@ed.ac.uk).

\section{REFERENCES}

Altarriba, J., Bauer, L. M., \& Benvenuto, C. (1999). Concreteness, context availability, and imageability ratings and word associations for abstract, concrete, and emotion words. Behavior Research Methods, Instruments, \& Computers, 31, 578-602.

Anderson, A. K. (2005). Affective influences on the attentional dynamics supporting awareness. Journal of Experimental Psychology: General, 134, 258-281.

Anderson, A. K., Christoff, K., Stappen, I., Panitz, D., GhahreMANI, D. G., GLOVER, G., ET AL. (2003). Dissociated neural representations of intensity and valence in human olfaction. Nature Neuroscience, 6, 196-202.

Anderson, A. K., Wais, P. E., \& Gabrieli, J. D. E. (2006). Emotion enhances remembrance of neutral events past. Proceedings of the $\mathrm{Na}$ tional Academy of Sciences, 103, 1599-1604.

BaAyen, R. H., Piepenbrock, R., \& van Rijn, H. (1993). The CELEX lexical database [CD-ROM]. Philadelphia: University of Pennsylvania, Linguistic Data Consortium.

Bird, H., Franklin, S., \& Howard, D. (2001). Age of acquisition and imageability ratings for a large set of words, including verbs and function words. Behavior Research Methods, Instruments, \& Computers, 33, 73-79.

Bonin, P., Méot, A., Aubert, L., Malardier, N., Niedenthal, P., \& CAPElle-ToczeK, M.-C. (2003). Normes de concrétude, de valeur d'imagerie, de fréquence subjective et de valence émotionnelle pour 866 mots [Concreteness, imageability, subjective frequency, and emotionality ratings for 866 words]. L'Année Psychologique, 103, 655-694.

Bradley, M. M. (1994). Emotional memory: A dimensional analysis In S. H. M. van Goozen, N. E. van de Poll, \& J. A. Sergeant (Eds.), Emotions: Essays on emotion theory (pp. 97-134). Hillsdale, NJ: Erlbaum.

Bradley, M. M., Greenwald, M. K., Petry, M. C., \& Lang, P. J. (1992). Remembering pictures: Pleasure and arousal in memory. Journal of Experimental Psychology: Learning, Memory, \& Cognition, 18, 379-390.

Bradley, M. M., \& Lang, P. J. (1999). Affective norms for English words $(A N E W)$ : Instruction manual and affective ratings. Gainesville: University of Florida, Center for Research in Psychophysiology.

Cahill, L., \& McGaugh, J. L. (1998). Mechanisms of emotional arousal and lasting declarative memory. Trends in Neurosciences, 21, 294-299.

Chiarello, C., Shears, C., \& Lund, K. (1999). Imageability and distributional typicality measures of nouns and verbs in contemporary English. Behavior Research Methods, Instruments, \& Computers, 31, 603-637.

Coltheart, M., Davelaar, E., Jonasson, J. T., \& Besner, D. (1977). Access to the internal lexicon. In S. Dornic (Ed.), Attention and performance VI (pp. 535-555). Hillsdale, NJ: Erlbaum.

Cortese, M. J., \& FugetT, A. (2004). Imageability ratings for 3,000 monosyllabic words. Behavior Research Methods, Instruments, \& Computers, 36, 384-387.

Danion, J.-M., Kauffmann-Muller, F., Grangé, D., ZimmerMANN, M.-A., \& GRETH, P. (1995). Affective valence of words, explicit and implicit memory in clinical depression. Journal of Affective Disorders, 34, 227-234.

Dolcos, F., LABAR, K. S., \& CABEZA, R. (2004). Dissociable effects of arousal and valence on prefrontal activity indexing emotional evaluation and subsequent memory: An event-related fMRI study. NeuroImage, 23, 64-74.

FERRAND, L. (2001). Normes d'associations verbales pour 260 mots "abstraits" [Word association norms for 260 "abstract" words]. L'Année Psychologique, 101, 683-721.

Graf, R., NAgler, M., \& JACOBS, A. M. (2005). Faktorenanalyze von 57 Variablen der visuellen Worterkennung [Factor analysis of 57 variables in visual word recognition]. Zeitschrift für Psychologie, 213, 205-218.

Hager, W., \& Hasselhorn, M. (1994). Über Variablen, die eingeschätzt werden sollen, und über Variablen, die eingeschätzt werden Emotionalität, Angenehmheit, Prägnanz, Erwünschtheit und Sympathie [On variables that should be estimated and variables that are estimated: Emotionality, pleasantness, meaningfulness, desirability, 
and likability]. In W. Hager \& M. Hasselhorn (Eds.), Handbuch deutschsprachiger Wortnormen (pp. 226-248). Göttingen: Hogrefe.

Hamann, S. B. (2001). Cognitive and neural mechanisms of emotional memory. Trends in Cognitive Sciences, 5, 394-400.

Hofmann, M. J., Kuchinke, L., Tamm, S., Võ, M. L.-H., \& Jacobs, A. M. (2009). Arousal accelerates lexical access in negatively valenced words. Manuscript submitted for publication.

Hofmann, M. J., Stenneken, P., ConRad, M., \& Jacobs, A. M. (2007). Sublexical frequency measures for orthographic and phonological units in German. Behavior Research Methods, 39, 620-629.

KeIL, A., \& IHSSEN, N. (2004). Identification facilitation for emotionally arousing verbs during the attentional blink. Emotion, 4, 23-35.

Kensinger, E. A. (2004). Remembering emotional experiences: The contribution of valence and arousal. Reviews in the Neurosciences 15, 241-251.

Kissler, J., Assadollahi, R., \& Herbert, C. (2006). Emotional and semantic networks in visual word processing: Insights from ERP studies. In S. Anders, G. Ende, M. Junghöfer, J. Kissler, \& D. Wildgruber (Eds.), Progress in brain research (Vol. 156, pp. 147-183). Amsterdam: Elsevier

Kissler, J., Herbert, C., Peyk, P., \& Junghöfer, M. (2007). Buzzwords: Early cortical responses to emotional words during reading. Psychological Science, 18, 475-480.

Kuchinke, L., Jacobs, A. M., Võ, M. L.-H., Conrad, M., Grubich, C., \& HerrmanN, M. (2006). Modulation of prefrontal cortex activation by emotional words in recognition memory. NeuroReport, 17, 1037-1041.

LANG, P. J. (1980). Behavioral treatment and bio-behavioral assessment: Computer applications. In J. B. Sidowski, J. H. Johnson, \& T. A Williams (Eds.), Technology in mental health and delivery systems (pp. 119-137). Norwood, NJ: Ablex.

Lang, P. J., Bradley, M. M., \& Cuthbert, B. N. (1998). Emotion, motivation, and anxiety: Brain mechanisms and psychophysiology. Biological Psychiatry, 44, 1248-1263.

Lang, P. J., Greenwald, M. K., Bradley, M. M., \& Hamm, A. O (1993). Looking at pictures: Affective, facial, visceral and behavioral reactions. Psychophysiology, 30, 261-273.

Maratos, E. J., Allan, K., \& RugG, M. D. (2000). Recognition memory for emotionally negative and neutral words: An ERP study. Neuropsychologia, 38, 1452-1465.

McGaugh, J. L. (2003) Memory and emotion: The making of lasting memories. London: Weidenfeld \& Nicolson.

McGaugh, J. L. (2006). Make mild moments memorable: Add a little arousal. Trends in Cognitive Sciences, 10, 245-247.

New, B., Pallier, C., Brysbaert, M., \& Ferrand, L. (2004). Lexique 2: A new French lexical database. Behavior Research Methods, Instruments, \& Computers, 36, 516-524.
Olsson, A., \& OCHSNER, K. N. (2008). The role of social cognition in emotion. Trends in Cognitive Sciences, 12, 65-71.

Paivio, A., Yuille, J. C., \& Madigan, S. A. (1968). Concreteness, imagery, and meaningfulness values for 925 nouns. Journal of Experimental Psychology Monographs, 76, 1-25.

Phelps, E. A. (2006). Emotion and cognition: Insights from studies of the human amygdala. Annual Review of Psychology, 57, 27-53.

Phelps, E. A., \& ANDERson, A. K. (1997). Emotional memory: What does the amygdala do? Current Biology, 7, R311-R314.

Phelps, E. A., LaBar, K. S., \& Spencer, D. D. (1997). Memory for emotional words following unilateral temporal lobectomy. Brain \& Cognition, 35, 85-109.

Redondo, J., Fraga, I., Padrón, I., \& Comesaña, M. (2007). The Spanish adaptation of ANEW (Affective Norms for English Words). Behavior Research Methods, 39, 600-605.

Richardson, M. P., Strange, B. A., \& Dolan, R. J. (2004). Encoding of emotional memories depends on amygdala and hippocampus and their interactions. Nature Neuroscience, 7, 278-285.

Russel, J. (1980). A circumplex model of affect. Journal of Personality \& Social Psychology, 39, 1161-1178.

Scott, G. G., O’Donnel, P. J., Leuthold, H., \& Sereno, S. C. (2009). Early emotion word processing: Evidence from event-related potentials. Biological Psychology, 80, 95-104.

Siegle, G. J. (1994). The Balanced Affective Word List Creation Program. Available at www.sci.sdsu.edu/CAL/wordlist.html.

Siegle, G. J., Ingram, R. E., \& Matt, G. E. (2002). Affective interference: An explanation for negative attention biases in dysphoria? Cognitive Therapy \& Research, 26, 73-88.

Thomas, L. A., \& LaBAR, K. S. (2005). Emotional arousal enhances word repetition priming. Cognition \& Emotion, 19, 1027-1047.

Võ, M. L.-H., JACOBS, A. M., \& ConRAD, M. (2006). Cross-validating the Berlin Affective Word List. Behavior Research Methods, 38 606-609.

Võ, M. L.-H., Jacobs, A. M., Kuchinke, L., Conrad, M., Schacht, A., \& HUTZLER, F. (2008). Emotion/cognition coupling in the eye: Introducing the pupil old/new effect. Psychophysiology, 45, 130-140.

Windmann, S., \& Kutas, M. (2001). Electrophysiological correlates of emotion-induced recognition bias. Journal of Cognitive Neuroscience, 13, 577-592.

Ziegler, J. C., Stone, G. O., \& Jacobs, A. M. (1997). What is the pronunciation for -ough and the spelling for $/ \mathrm{u} /$ ? A database for computing feedforward and feedback consistency in English. Behavior Research Methods, Instruments, \& Computers, 29, 600-618.

(Manuscript received August 19, 2008; revision accepted for publication November 10, 2008.) 